\title{
RESEARCHES REGARDING STRUCTURAL CHARACTERISTICS OF A NEW COMPLEX CONCENTRATED ALLOY OBTAINED BY RAPID SOLIDIFICATION
}

\author{
1,2loana ANASIEI, ${ }^{1,2}$ loana Cristina BADEA, ${ }^{1}$ Beatrice Adriana SERBAN, ${ }^{1}$ Mihai Tudor OLARU, \\ ${ }^{1}$ Denisa VONICA, ${ }^{1,2}$ Lidia LICU, ${ }^{1}$ Marian BURADA, ${ }^{1}$ Dumitru MITRICA, \\ ${ }^{1}$ National $R \& D$ Institute for Nonferrous and Rare Metals—IMNR, Pantelimon, Ilfov, Romania, \\ cristina.banica@imnr.ro \\ ${ }^{2}$ University Politehnica of Bucharest, Bucharest, Romania
}

https://doi.org/10.37904/metal.2021.4225

\begin{abstract}
In the recent years it has been a tremendous interest in the complex concentrated alloys (CCAs), due to their novelty introduced by the multiple principal elements concept. As a new generation of structural materials, CCAs have the potential for a promising range of properties. CCAs consist of a mixture of four or more elements in high proportion, provided by a wide compositional space. The high mixing entropy of CCAs generates structures containing complex solid solution and well dispersed intermetallic phases. Many CCA systems cover a wide range of mechanical and physical properties, like strength, toughness, stiffness and oxidation resistance. The present work analyses the AICuSiZnMg alloy system, which presents a significant potential in applications with intensively corrosive work conditions. Thermodynamic and kinetic criteria were calculated for the multicomponent alloy system, to obtain the most appropriate proportion for each element. In addition, MatCalc simulating program was used to model the growth of the precipitated phases during solidification processes. This optimisation of the rapid solidification process was accomplished to obtain the best structural particularities needed for the required properties. The selected alloy was prepared by induction melting process and rapid solidified by melt spinning technique. The resulted samples were analysed by physical-chemical and microstructural techniques and the empirical results were compared to the modelling findings to correlate the obtained properties and to estimate the final performances of the alloy.
\end{abstract}

Keywords: Complex concentrated alloys, ribbons, modelling, melt-spinning

\section{INTRODUCTION}

Complex concentrated alloys (CCAs) are a new family of materials, preponderantly based on solid solution structures, that possess a vastly spectrum of properties, including corrosion resistance or improved toughness. The obtaining process of CCAs is more complex compared with traditional alloys, because of the large number of possible combination elements that are mixed together [1]. The multicomponent character of CCAs and the main core effects influence the microstructure and the potential of supporting improved mechanical properties at high temperatures [2]. The properties of the CCAs depend of each element characteristics and their concentration, so that by modifying the composition, the properties and structural particularities of the alloy are significantly different from the initial one [3].

The flexibility in choosing the alloy composition from a multitude of elements determines the properties of the selected CCA. Increasing or decreasing the proportion of each element can have a significant influence on the alloy microstructure and applications. To have a good corrosion resistance, CCAs have in their composition high contents of chromium, aluminum, molybdenum, titanium and other passivation elements [4]. 
To obtain complex concentrated alloys with more refined and homogeneous structures is used an unconventional technique, called rapid solidification, using the melt - spinning process. The particularity of this technology is the formation of amorphous alloys [5] in the form of ribbons, as a result of the almost instantaneously cooling of the alloy that reaches to $10^{6} \mathrm{~K} / \mathrm{s}$ [6-11]. The process also leads to the formation of non-equilibrium phases, such as supersaturated solid solutions, that are considered important characteristics of CCAs [12].

The aim of this study is to obtain CCAs with advanced properties that have applicability in special conditions, such as intensive corrosive environments. In this context, a rigorous selection process was applied to identify the most suitable chemical composition and proportion of the used elements. By applying thermodynamic and kinetic models and MatCalc computer simulations it was determined an optimal composition of the alloys [2]. These processes are followed by elaboration phase that is performed using the melt - spinning equipment, on different rotation rates, between 500 and $1500 \mathrm{rpm}$. The obtained alloys are chemically, physically and structurally characterized and the empirical results were linked with the potential and future development trends $[13,14]$.

\section{METHODS}

Modelling and experimental results were compared in this paper. The MatCalc Pro edition software, version 6.02 , was used to determinate the multi-phase precipitation kinetics of the alloy. Thermodynamic and kinetic databases Me-AL 2019 were used for calculations.

The alloy $\mathrm{Al}_{5} \mathrm{Cu}_{0.5} \mathrm{Si}_{0.2} \mathrm{Zn}_{1.5} \mathrm{Mg}_{0.2}$ was obtained by melting in an induction furnace Linn MFG-300, under controlled atmosphere and cast in a copper mould. The properties of the selected elements were studied to determine the required concentration. The order in which the metals were placed in the furnace was influenced by their melting temperature and reactivity. The alloy ribbons were obtained by melt - spinning technique. Different rotation rates were performed to determine the influence on the final structure. The as-cast and meltspun samples were analysed by specific chemical and structural characterisation methods.

In order to determine the chemical composition, an inductively coupled plasma spectrometry (ICP-OES) method was applied, using an Agilent 725 spectrometer. The alloy microstructure was investigated by optical analyses with a Zeiss Axio Scope A1m Imager microscope and by scanning electron microscopy (SEM) method, using a FEI Quanta 3D FEG microscope. To determine the phase configuration, the X-ray diffractometry (XRD) analysis was performed. Data acquisition was accomplished on the BRUKER D8 ADVANCE diffractometer with the help of DIFFRACplus XRD software, version 2018.

\section{EXPERIMENTAL PROCEDURES}

\subsection{Kinetics simulation}

The multi-phase precipitation kinetics of the alloy was determined using MatCalc Pro edition, version 6.02. The simulation results display the structural behaviour during the melt-spinning process (Figure 1). In Figure 1a is shown the fast-cooling rate. The variation of the precipitated phase fraction with time is presented in Figure $\mathbf{1 b}$ and it can be seen that MG2SI forms first and has the higher proportion in the material. The simulation does not show a comparable phase fraction for THETA_Al $2 \mathrm{Cu}$ and $\mathrm{LC14} \mathrm{Zn}_{2} \mathrm{Mgand}$ indicates a significantly lower composition. The volume of precipitates increases with time until $0.8 \mathrm{~s}$ and then remains constant (Figure 1c). In Figure 1d it can be observed that the tendency of the precipitate mean radius is to increase rapidly and then decrease after $0.5 \mathrm{~s}$, becoming stable at the end of the cycle. 
a.

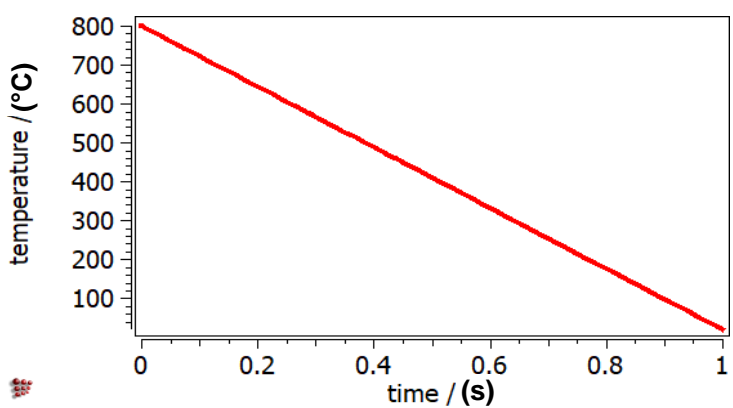

c.

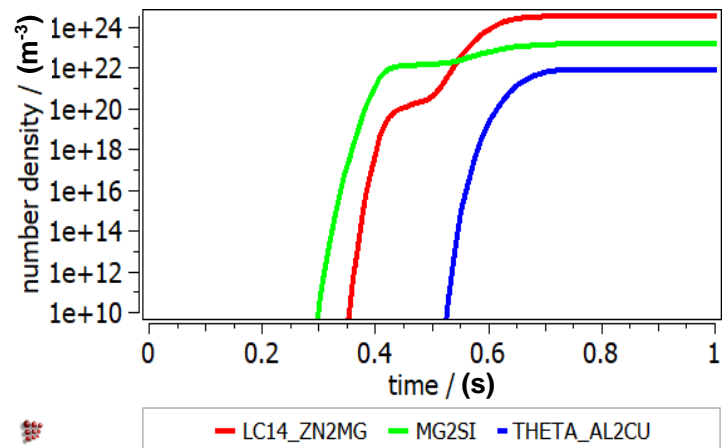

b.
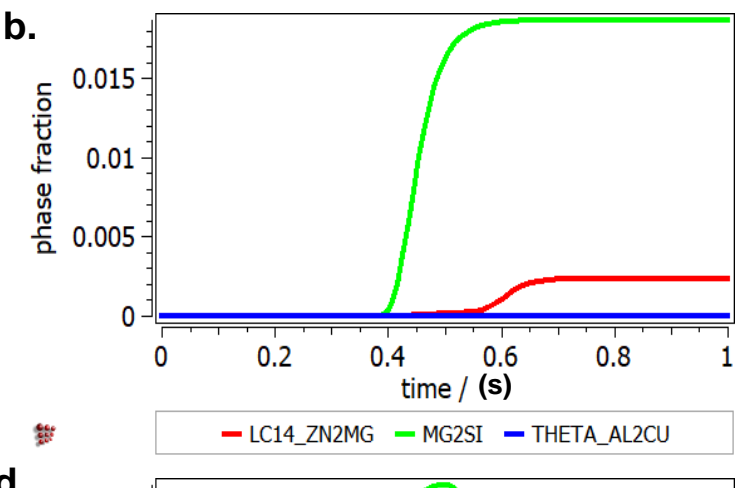

d.

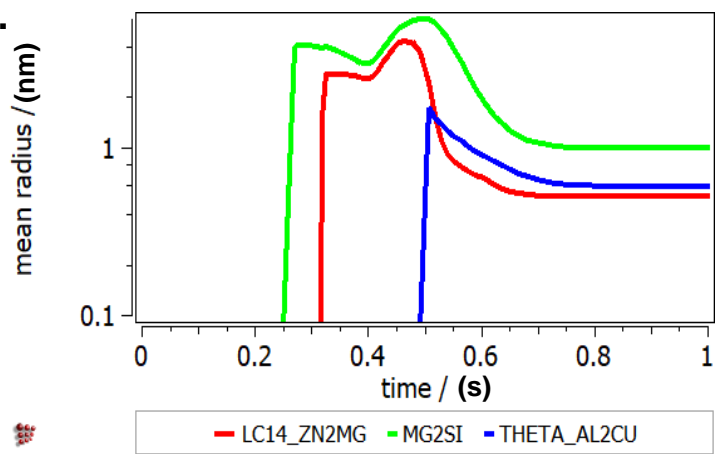

Figure 1 Precipitation kinetics in $\mathrm{Al}_{5} \mathrm{Cu}_{0.5} \mathrm{Si}_{0.2} \mathrm{Zn}_{1.5} \mathrm{Mg}_{0.2}$ alloy during rapid solidification: a. rapid solidification diagram, b. precipitate phase fraction versus time, c. precipitate number density versus time, d. precipitate mean radius versus time

\section{EXPERIMENTAL RESULTS}

The chemical composition of the alloy is observed in Table 1. Most elements, except aluminium, had an experimental composition in a maximum range of $2 \mathrm{wt} \%$ compared with the nominal values. Because the elements are found in a high percentage, such a variation does not significantly affect the structural behaviour of the alloy.

Table 1 Chemical composition of the $\mathrm{Al}_{5} \mathrm{Cu}_{0.5} \mathrm{Si}_{0.2} \mathrm{Zn}_{1.5} \mathrm{Mg}_{0.2}$ alloy (wt\%)

\begin{tabular}{|c|c|c|c|c|c|}
\hline $\mathbf{A l}_{\mathbf{5}} \mathbf{C u}_{0.5} \mathbf{S i}_{0.2} \mathbf{Z n}_{\mathbf{1} .5} \mathbf{M g}_{0.2}$ alloy & Al & $\mathbf{C u}$ & $\mathbf{S i}$ & $\mathbf{Z n}$ & $\mathbf{M g}$ \\
\hline Nominal composition & 49 & 11.54 & 2.05 & 36.64 & 1.77 \\
\hline Experimental composition & 43.86 & 11.39 & 2.02 & 38.66 & 2.02 \\
\hline
\end{tabular}

The as-cast alloy and ribbons were studied to analyze the structural composition of the material (Figure 2). From the study performed on the as-cast alloy it can be observed that besides the three constituent dendritic phases there are also interdendritic phases of a Chinese script morphology eutectic and of a punctiform and lamellar eutectic (Figure 2a). The ribbon obtained on a rotation speed of the $500 \mathrm{rpm}$ had three phases, one of which is dendritic and one eutectic developed in the interdendritic space (Figure 2b). But in the case of the ribbons obtained on a rotation speed of the $1000 \mathrm{rpm}$ and $1500 \mathrm{rpm}$, no other phases than the dendritic ones were identified (Figures $\mathbf{2 c}$ and $\mathbf{d}$ ). All the microstructures were recorded at the largest magnification of the microscope, but even so, in Figure $\mathbf{2} \mathbf{d}$ the width of the ribbon can be seen.

The as-cast and ribbons alloys were analyzed using scanning electric microscopy (Figure 3). The alloy was characterized by a finer dendritic structure in the marginal area, compared to the central area where the dendritic structure is coarser. There were observe two main phases, a dendritic phase containing mostly $\mathrm{Al}$ and $\mathrm{Zn}$, and a second main phase, interdendritically located, containing mostly $\mathrm{Cu}$ and Al. The ribbons in Figure $3 \mathbf{c}$ and $\mathbf{d}$ had a single phase, while in the case of the ribbons obtained on a rotation speed of $500 \mathrm{rpm}$ (Figure 3b) were identified other compounds and an eutectic developed in the interdendritic space. 

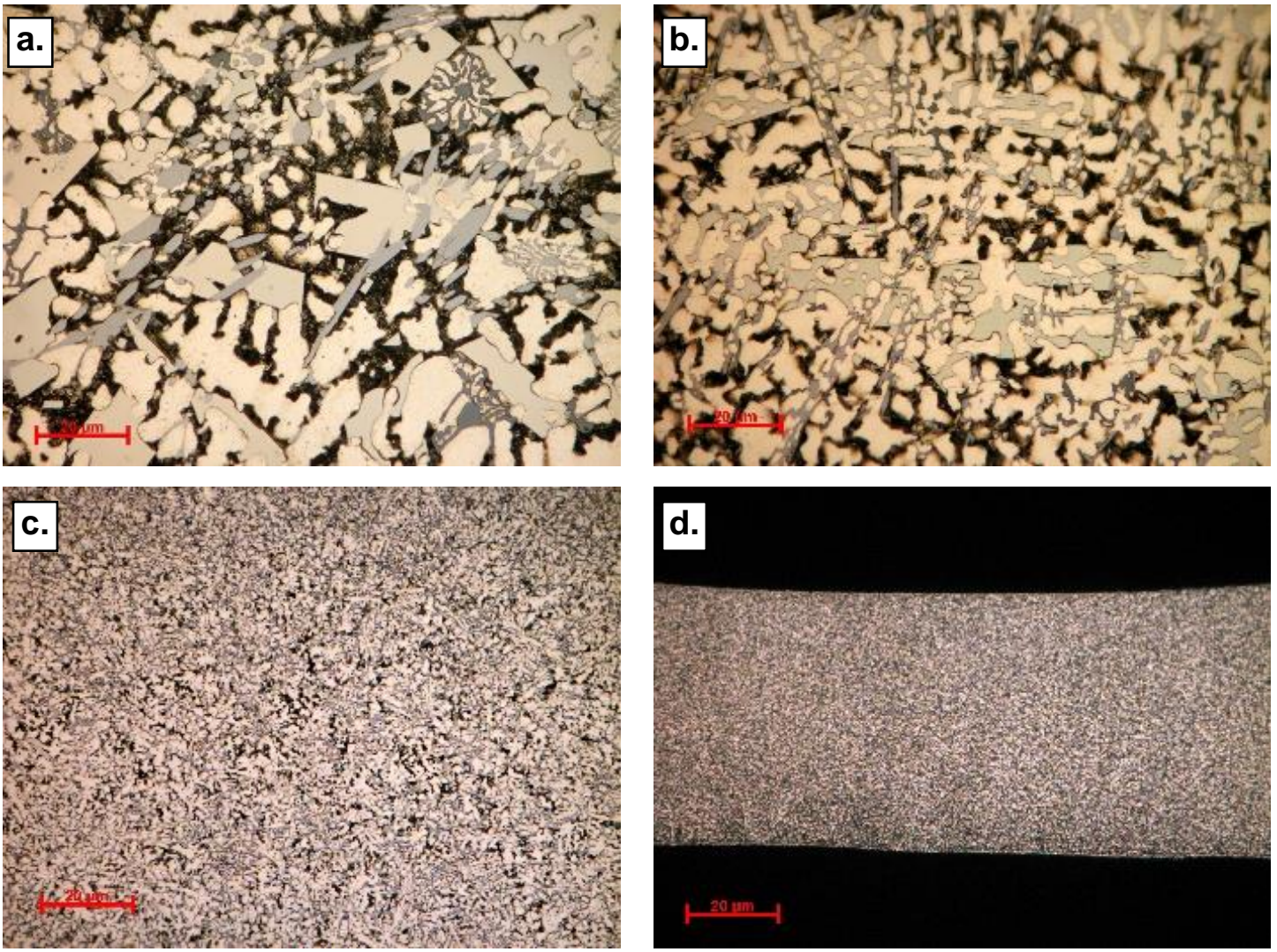

Figure 2 Microstructures for $\mathrm{Al}_{5} \mathrm{Cu}_{0.5} \mathrm{Si}_{0.2} \mathrm{Zn}_{1.5} \mathrm{Mg}_{0.2}$ alloy: a. as-cast alloy, b. ribbon obtained at a rotation speed of $500 \mathrm{rpm}$, c. ribbon obtained at a rotation speed of $1000 \mathrm{rpm}$, d. ribbon obtained at a rotation speed of $1500 \mathrm{rpm}$
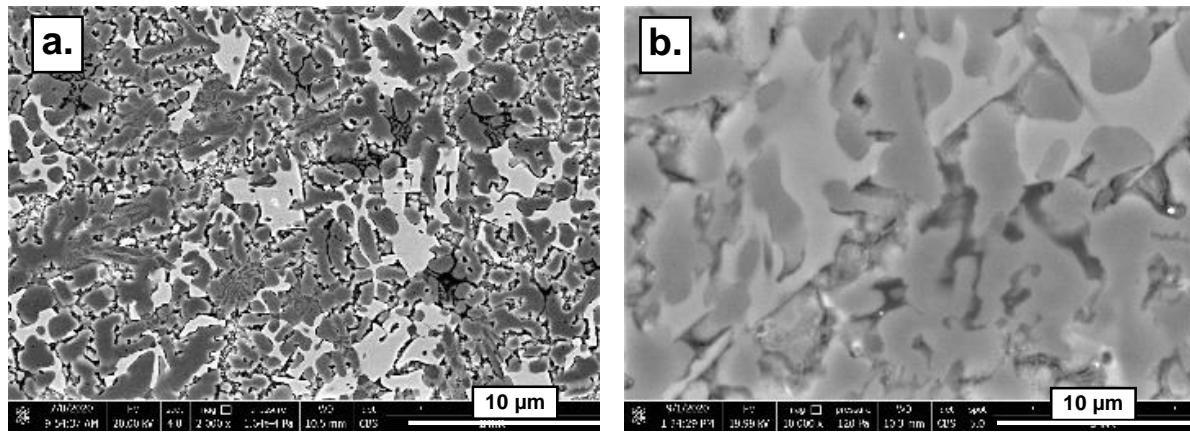

Figure 3 SEM image for $\mathrm{Al}_{5} \mathrm{Cu}_{0.5} \mathrm{Si}_{0.2} \mathrm{Zn}_{1.5} \mathrm{Mg}_{0.2}$ alloy:
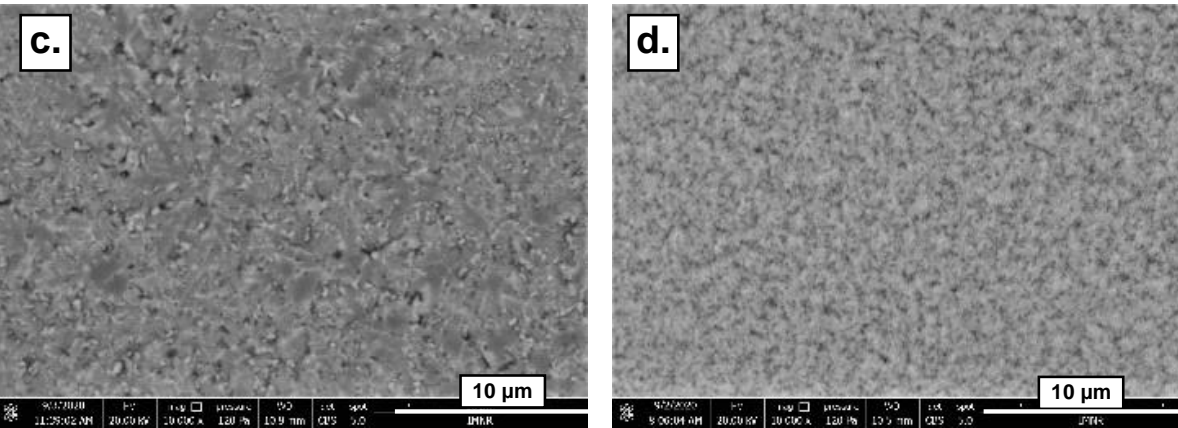

a. as-cast alloy,

b. ribbon obtained at a rotation speed of $500 \mathrm{rpm}$,

c. ribbon obtained at a rotation speed of the 1000 rpm,

d. ribbon obtained at a rotation speed of $1500 \mathrm{rpm}$

By optical analysis and scanning electron microscopy analysis was observed the tendency of the ribbons to form finer dendritic structures with the increasing of the solidification rate. The ribbons obtained at the rotation 
speed of $1500 \mathrm{rpm}$ had the finest and most homogeneous structure, which could also be observed by EDS analysis (Figure 4).
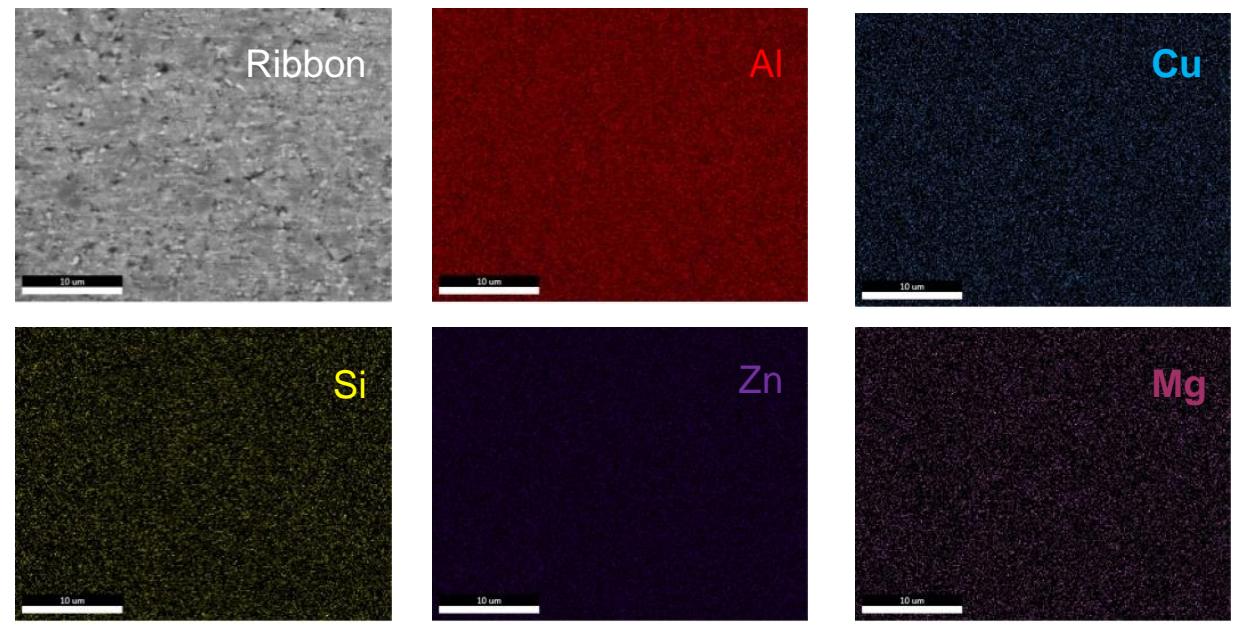

Figure 4 EDS mapping of ribbon obtained at the rotation speed of $1500 \mathrm{rpm}$ of the $\mathrm{Al}_{5} \mathrm{Cu}_{0.5} \mathrm{Si}_{0.2} \mathrm{Zn}_{1.5} \mathrm{Mg}_{0.2}$ alloy

$\mathrm{DRX}$ analysis of the ribbons obtained at the rotation speed of $1500 \mathrm{rpm}$ was presented in Figure 5. According to the experimental results, two new phases $\left(\mathrm{Al}_{4.3} \mathrm{Cu}_{3.2} \mathrm{Zn}_{0.7}\right.$ and $\left.\mathrm{Mg}_{8} \mathrm{Cu}_{2} \mathrm{Al}_{4} \mathrm{Si}_{7}\right)$ appear in the ribbon structure, which were not identified in the modelling process. However, the $\mathrm{Mg}_{2} \mathrm{Si}$ phase was identified in the modelling results but it was not detected in the XRD reports. Modelling is a method by which one can approximate the constituent phases that can be formed during the alloy solidification, so it is possible to have certain discrepancies between the empirical results and the simulated ones. Non-equilibrium structures, which can be obtained in practice through regular casting, are different in reality from the structures calculated by semi-ideal algorithms, based on conventional diffusion databases.

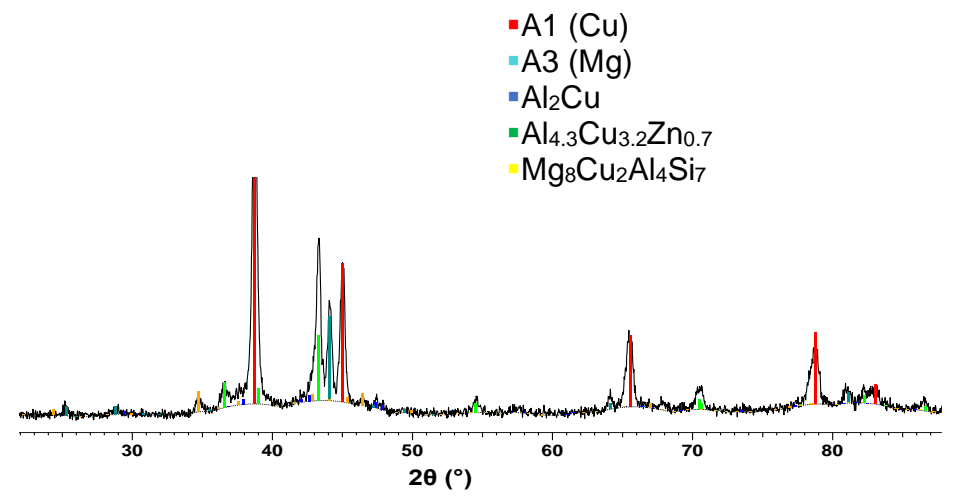

Figure 6 Graphic presentation of the qualitative phase analysis by DRX for a ribbon obtained at a rotation speed of $1500 \mathrm{rpm}$ of the $\mathrm{Al}_{5} \mathrm{Cu}_{0.5} \mathrm{Si}_{0.2} \mathrm{Zn}_{1.5} \mathrm{Mg}_{0.2}$ alloy

\section{CONCLUSION}

In the research paper, the alloy $\mathrm{Al}_{5} \mathrm{Cu}_{0.5} \mathrm{Si}_{0.2} \mathrm{Zn}_{1.5} \mathrm{Mg}_{0.2}$ was studied by analyzing the cast samples obtained by rapid solidification process. Using the MatCalc Pro edition program to simulate the rapid solidification of the CCA it was observed that the precipitated phases are: A1_FCC, $\mathrm{Mg}_{2} \mathrm{Si}, \mathrm{Zn}_{2} \mathrm{Mg}, \mathrm{Al}_{2} \mathrm{Cu}$. Analyzing their evolution in time, it was observed that the $\mathrm{Mg}_{2} \mathrm{Si}$ phase has higher proportion and is the most stable. The alloy ribbons obtained at different rotation rates of the support disk have different characteristics in terms of structural homogeneity and the size of the grains formed. The ribbons obtained at $1500 \mathrm{rpm}$ do not contain visible 
eutectic formations. Also, the size of the ribbons varied significantly between the samples obtained at $500 \mathrm{rpm}$, $1000 \mathrm{rpm}$ and $1500 \mathrm{rpm}$. The structure of the ribbons contained different phases compared with those obtained in the simulation through the MatCalc program. Therefore, the phases $\mathrm{Al}_{4.3} \mathrm{Cu}_{3.2} \mathrm{Zn}_{0.7}$ and $\mathrm{Mg}_{8} \mathrm{Cu}_{2} \mathrm{Al}_{4} \mathrm{Si}_{7}$ were not predicted by the modelling software but were found in the solidified specimen.

\section{ACKNOWLEDGEMENTS}

This work was supported by research grant of the Romanian National Authority for Scientific Research and Innovation, CNCS/CCCDI - UEFISCDI, project number: 20PCCDI/2018, within PNCDI III.

\section{REFERENCES}

[1] AMIRI, A., SHAHBAZIAN-YASSAR, R. Recent progress of high-entropy materials for energy storage and conversion. Journal of Materials Chemistry A. 2021, vol. 9, pp. 782-823.

[2] MITRICA, D. et al. Modeling and experimental results of selected lightweight complex concentrated alloys, before and after Heat Treatment. Materials. [online]. 2020, vol. 13, no. 19, p. 4330. Available from: https://doi.org/10.3390/ma13194330

[3] GAO, M.C., YEH, J.-W., LIAW, P.K., ZHANG, Y. High-entropy alloys: Fundamentals and applications. Cham Switzerland: Springer: Cham, 2016.

[4] YU, F. et. al. Recent advances on environmental corrosion behavior and mechanism of high-entropy alloys. Journal of Materials Science \& Technology. [online]. 2020, vol. 80, pp. 217-233. Available from: https://doi.org/10.1016/j.jmst.2020.11.044.

[5] SURYANARAYANA, C. Rapid solidification processing. In: VCH, Weinheim, Germany: R.W. Cahn (Ed.), Processing of Metals and Alloys. Materials Science and Technology - A comprehensive treatment. 1991, vol. 15. pp. 57-110.

[6] BLAZ, L. et al. Structure and properties of $6061+26$ mass $\%$ Si aluminum alloy produced via coupled rapid solidification and KOBO-extrusion of powder. Journal of Materials Processing Technology. [online]. 2009, vol. 209, no. 9, pp. 4329-4336. Available from: https://doi.org/10.1016/j.jmatprotec.2008.11.012.

[7] KULA, A., BLAZ, L., LOBRY, P. Structure and properties studies of rapidly solidified Al-Mn alloys, Key Engineering Materials. [online]. 2016, vol. 682, pp. 199-204. Available from: https://doi.org/10.4028/www.scientific.net/KEM.682.199.

[8] LAVERNIA, E.J., SRIVATSAN, T.S., The rapid solidification processing of materials: science, principles, technology, advances, and applications, Journal of Materials Science. [online]. 2010, vol. 45, no. 2, pp. $287-325$. Available from: https://doi.org/10.1007/s10853-009-3995-5.

[9] ZHOU, T. et al. Investigation on microstructure characterization and property of rapidly solidified Mg-Zn-Ca-Ce-La alloys. Materials Characterization. [online]. 2012, vol. 63, pp 77-82. Available from: https://doi.org/10.1016/j.matchar.2011.10.004.

[10] ZHOU, T. et al. Microstructure and mechanical properties of rapidly solidified/powder metallurgy Mg-6Zn and Mg6Zn-5Ca at room and elevated temperatures, Journal of Alloys and Compounds. [online]. 2013, vol. 560, pp. 161166. Available from: https://doi.org/10.1016/j.jallcom.2013.01.066.

[11] KULA, A., TOKARSKI, T., NIEWCZAS, M. Comparative studies on the structure and properties of rapidly solidified and conventionally cast AM60 magnesium alloys. Materials Science \& Engineering A. [online]. 2019, vol. 759, pp. 346-356. Available from: https://doi.org/10.1016/j.msea.2019.05.044.

[12] SHERIF EL-ESKANDARANY, M. Mechanical Alloying 2nd Edition. Mechanical Alloying (Second Edition). Nanotechnology, Materials Science and Powder Metallurgy. [online]. 2015, pp 1-12. Available from: http://dx.doi.org/10.1016/B978-1-4557-7752-5.00001-2.

[13] DUMITRU, M. et al. Complex concentrated alloys for substitution of critical raw materials in applications for extreme conditions. Materials . [online]. 2021, vol. 14, no. 5, p. 1197. Available from: https://doi.org/10.3390/ma14051197.

[14] MANZONIA, A. M., GLATZEL, U. New multiphase compositionally complex alloys driven by the high entropy alloy approach. Materials Characterization. [online]. 2019, vol. 147, pp. 512-532. Available from:

https://doi.org/10.1016/j.matchar.2018.06.036. 